\title{
Economic evaluation of spondyloarthritis: economic impact of diagnostic delay in Italy
}

This article was published in the following Dove Press journal:

ClinicoEconomics and Outcomes Research

\author{
Francesco S Mennini ${ }^{1,2}$ \\ Raffaella Viti' \\ Andrea Marcellusi ${ }^{1-3}$ \\ Paolo Sciattella' \\ Ombretta Viapiana ${ }^{4}$ \\ Maurizio Rossini ${ }^{4}$ \\ 'Economic Evaluation and HTA \\ (EEHTA), CEIS, Faculty of Economics, \\ University of Rome "Tor Vergata", \\ Rome, Italy; 'Institute of Leadership \\ and Management in Health, Kingston \\ University, London, UK; ${ }^{3}$ Consiglio \\ Nazionale delle Ricerche (CNR), \\ Istituto di Richerche sulla Popolazione \\ e le Politiche Sociali (IRPPS), \\ Rome, Italy; ${ }^{4}$ Rheumatology Unit, \\ Department of Medicine, University \\ of Verona, Verona, Italy
}

Background and aim: Spondyloarthritis ( $\mathrm{SpA})$ is a disease that normally affects the axial skeleton. It progressively leads to overall stiffness up to severe postural deformity of rachis and functional impotence. The objective of the study was to quantify, through an economic model, the impact of specialized testing and pharmacological treatments carried out by the National Health Service (NHS) in normal clinical practice, before the patient is diagnosed with SpA in Italy. In line with the analysis objective, the chosen perspective is that of the NHS.

Method: The study was conducted by analyzing the Health Search Database - IMS Health Longitudinal Patient Database, from which newly diagnosed SpA patients were identified over the period 1 January 2007 to 31 December 2013. The use of specialist health care services and pharmacological treatments provided to the patients before the final SpA diagnosis were estimated. Results: Through a retrospective analysis of the Health Search Database, 1,084 subjects (aged 25-45 years) were identified. These patients produced an expense of approximately $€ 153,000$ in the 3 years prior to a confirmed SpA diagnosis, in terms of specialist check-ups and drugs, presumably not appropriately used due to a lack of diagnosis. If we assume that the Health Search Database is a representative sample of the Italian population, it may be estimated that, in the 3 years prior to $\mathrm{SpA}$ diagnosis, over $€ 5.4$ million was largely unduly spent in Italy to examine and manage 38,232 newly diagnosed SpA patients, between 2010 and 2013.

Conclusion: The costs due to the delay in SpA diagnosis were quantified for the first time in Italy. For this reason, this work represents a contribution for national and regional decision makers to understand the current clinical practice and the economic consequences of a diagnostic delay in the short and medium term.

Keywords: spondyloarthritis, cost of illness, direct cost, claims database, Italy

\section{Introduction}

Spondyloarthritis $(\mathrm{SpA})$ is a disease that normally affects the axial skeleton. It progressively leads to overall stiffness up to severe postural deformity of rachis and functional impotence. SpA also includes psoriatic arthritis, arthritis associated with inflammatory bowel disease, and reactive arthritis. The term SpA covers both patients who have already developed structural damage in the sacroiliac joints or spine visible on radiographs (radiographic axial SpA, also termed ankylosing spondylitis [AS]) and patients without such structural damage, labeled as non-radiographic SpA. The disease usually starts in the third decade of life with a male to female ratio of two to one for radiographic SpA and of one to one for non-radiographic SpA. More than $90 \%$ heritability
Correspondence: Francesco S Mennin Centre for Economic and International Studies (CEIS), University of "Tor Vergata", Via Columbia, 2, Rome, Italy Tel +39333499 I647

Email f.mennini@uniroma2.it 
has been estimated, the highest genetic association being with HLA-B27. Patients present with chronic back pain and stiffness predominantly of the pelvis and the lower back, but any part of the spine can be involved. A typical symptom is inflammatory back pain, which is clinically defined. Patients complain of morning stiffness mostly of the lower back with improvement on exercise but not by rest. They can also be awakened by back pain in the night, typically in the second part of the night. Several clinical indices (presence of chronic back pain starting at an age $\leq 45$ years, inflammatory back pain, peripheral and extra-articular manifestations, response of symptoms to non-steroidal anti-inflammatory drugs [NSAIDs], family history of SpA and related disorders), and several laboratory indices (HLA-B27 and acute phase reactants testing, and imaging findings) have to be combined for classification and diagnosis of SpA. The development of new criteria for classification and for screening of patients with axial SpA have been crucial for the early identification and treatment of such patients, with magnetic resonance imaging being the most important existing imaging method.

The reported prevalence of $\mathrm{SpA}$ is between $0.32 \%$ and $1.4 \%$ in different surveys. ${ }^{1,2}$ According to the ethnic group and the diagnostic criteria used, prevalence of AS ranges between $0.06 \%$ and $0.2 \%{ }^{1,2}$ Its incidence is approximately 6-7 patients in 100,000 adults per year. ${ }^{3}$ This disease causes high use of health services, reduced productivity, and a limited working capacity in the patients. ${ }^{4}$

SpA has a significant impact on the patient's life, especially in terms of quality of life. Literature data indicate that the patients are subject to different physical constraints, causing limited working capacity and affecting social relationships and family life. From an economic point of view, the main cost factor is represented by the reduced physical functions. ${ }^{5}$

In terms of economic burden, many studies demonstrated that SpA (mainly AS) causes high social and medical costs. ${ }^{5-14}$ Indirect costs linked to the days of absence from work together with the loss of related productivity - are the most important determinant of total costs. ${ }^{7,8}$

This can partially explain the association between total costs and disease severity. A recent revision by Palla et $\mathrm{al}^{4}$ summarizes the estimated direct and indirect costs in different countries.

As of today, the economic burden of SpA in Italy is not directly known, but some studies estimated that the annual social cost incurred for AS patients treated with biological drugs accounts for approximately $€ 20$ million in Italy. These patients represent only $22 \%$ of the diagnosed ones. ${ }^{15,16}$
Diagnostic delay is one of the key clinical challenges of SpA. ${ }^{17}$ The average time span from the symptom onset to the definitive diagnosis is $8-10$ years. ${ }^{17}$ This diagnostic delay has a negative impact not only on the patient, but potentially, also on the disease progression and on the directly related costs incurred by National Health Service (NHS) and society as a whole (indirect costs). The delayed diagnosis causes delay in management and in potential advantages derived from the slowdown of the disability and the improvement of the quality of life.

A delay in diagnosis of 8.57 years was estimated in the UK population, causing loss of spine mobility and inability to work in working-age patients. ${ }^{18}$ NSAIDs and blockers of cytokines TNF- $\alpha$ and IL-17 are effective therapies. Early treatment with NSAIDs, as well as a diagnosis within 4 years from the disease onset in patients starting an anti-TNF therapy, may reduce the progression of the radiographic damage. Anti-TNF therapy gives a better response if the duration of the disease symptoms is shorter than 10 years. ${ }^{18}$ The main reason for the delay in diagnosis is due to the fact that spinal pain is an extremely common condition and, in most cases, it is not due to severe causes. Furthermore, old diagnostic criteria require significant radiographic lesions, normally arising at a later stage, while routine laboratory tests often supply results in the range for this kind of disease. Conversely, the new diagnostic criteria available today should allow an earlier diagnosis of SpA patients. ${ }^{19}$

The objective of the study was to quantify, through an economic model, the impact of specialized testing and pharmacological treatments carried out by the NHS in normal clinical practice, before the patient is diagnosed with $\mathrm{SpA}$ in Italy. In line with the analysis objective, the chosen perspective is that of the NHS.

\section{Methods}

The study was conducted by analyzing the HSD, from which newly diagnosed SpA patients were identified over the period 1 January 2007 to 31 December 2013. The use of specialist health care services and pharmacological treatments provided to the patients before the final SpA diagnosis were estimated.

\section{Data sources}

Data were processed through a descriptive inquiry of the HSD, created by the Italian Society of General Medicine and Primary Care in $1998 .^{20}$ The database includes a wide and representative sample of the Italian population and is aimed at collecting information derived from the daily clinical practice of general practitioners (GPs). 
GPs are selected so as to include a proportional number of patients to the population size of the respective geographical areas. When this study was conducted, Health Search contained information of over 900 Italian practitioners, and a total sample of more than 1.5 million patients.

According to the selection criteria used by the Health Search network researchers, the population represented in the database is distributed by sex and age, in line with the general Italian adult population of ISTAT data. ${ }^{21}$

The information collected by each GP is representative of the daily clinical practice and contains demographic and clinical information (i.e., diagnoses, laboratory tests with results, hospitalizations, etc.), drug prescriptions, prevention data (i.e., blood pressure, body mass index, smoking, etc.). These data are associated with an identification code of the patient, according to the classical criteria of a relational database.

Furthermore, a lot of this information is directly codified according to the standards commonly used by the NHS for reimbursements, applying the national health care range of fees. For each single drug a pharmaceutical database reports the Anatomical Therapeutic Chemical classification (ATC code), the molecule, the trade name, and the MINSAN code (the code assigned by the Health Ministry to each specific drug when placed on the market).

\section{Enrollment criteria}

First, the population to be included in the economic analysis was identified. Specifically, within the database, the patients with at least an SpA diagnosis were identified (code ICD-9 720: "Ankylosing spondylitis and other inflammatory spondylopathies") over the period 1 January 2010 to 31 December 2013. This code includes the following subgroups of diseases:

- 720.0 "Ankylosing spondylitis";

- 720.1 "Spinal enthesopathy";
- 720.2 "Unclassified sacro-iliitis";

- 720.8 "Other inflammatory spondylopathies";

- 720.9 "Unspecified inflammatory spondylopathy”.

Among the SpA-diagnosed subjects, only the patients who had received a confirmed diagnosis (by the GP with 720 diagnosis code) during the following year were selected. Finally, in order to identify only the newly diagnosed patients, the subjects who had used health care services due to SpA in the previous 3 years were excluded.

Therefore, all the newly diagnosed SpA patients during the year were selected.

The economic analysis was based only on the patients aged 25-45 years, in order to consider an age group that actually included newly diagnosed SpA patients. The selection process of the population being considered is reported in Figure 1.

\section{Economic analysis}

Based on the selected population, all specialist and pharmaceutical services correlating with potential symptoms or manifestations of SpA that took place in the 3 years prior to the first $\mathrm{SpA}$ diagnosis were considered, in order to quantify the amount and type of health care services provided before the real diagnosis. In particular, according to the clinical expert opinion of two rheumatologists, co-authors of this study, the SpA-specific health care services that could have allowed an early diagnosis of $\mathrm{SpA}$ (Supplementary material) were selected. In order to have a conservative analysis, only services strictly related to SpA diagnosis were considered.

The economic quantification of specialist services was carried out matching the reimbursement fee of the national health care range of fees ${ }^{22}$ to each service and adding up the costs incurred by each patient in the period of analysis.

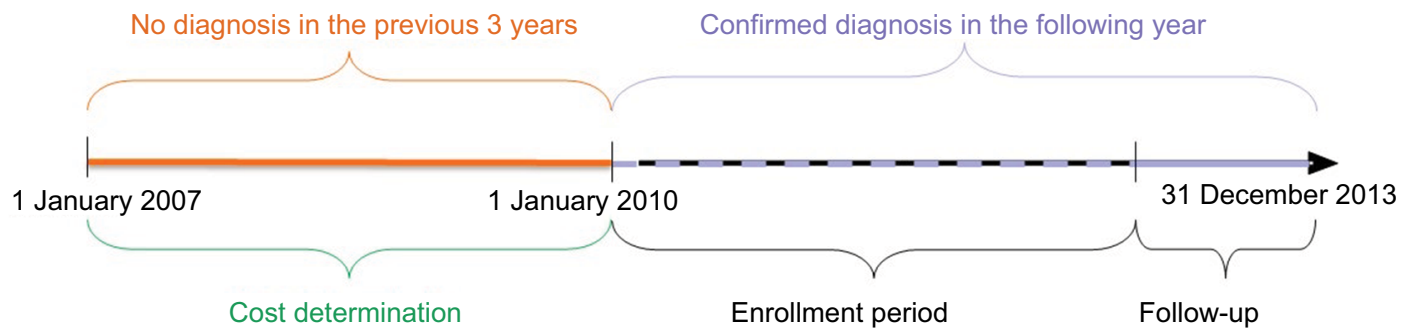

Period of analysis observation

Figure I Selection criteria for new SpA patients aged 25-45 years. Abbreviation: SpA, spondyloarthritis. 
The same procedure was carried out for pharmaceutical prescriptions, taking into account the prices available in the pharmaceutical manual associated with each AIC code being analyzed (code of marketing authorization issued by the Italian Medicines Agency). ${ }^{23}$

In order to obtain a reliable quantification of the expense incurred for these services nationally, the economic model assumed that the analyzed population is a representative sample of the national population. Therefore, an inference analysis was carried out, adjusting the services and related costs to the total resident population in Italy in the same period of analysis.

\section{Ethical statement}

Ethical approval was not required due to the Health Search IMS Health Longitudinal Patient Database (HSD) being a longitudinal primary care medical record database that was set up by members of the Italian College of General Practitioners (SIMG). The HSD contains anonymized clinical data (diagnoses, patient referrals, hospital admissions, and clinical investigations' results) and prescription data (drug name, prescription date, number of days' supply given) for all the medications which are reimbursed by the Italian NHS, and is available to researchers on request.

\section{Results}

In the total population of the Health Search sample, 6,461 in $1,549,417$ subjects received at least an $\mathrm{SpA}$ diagnosis over the considered period of analysis. Of these, 3,142 patients (48.6\%) were excluded due to the lack of diagnosis by the GP in the following year. An additional 958 patients were excluded because they were already diagnosed as having SpA in the 3 years prior to the index date. Finally, the patients' extraction in the reference age group was 1,084 subjects, corresponding to an incidence of 2.2 per 1,000 in the $25-45$ year old population of the analyzed sample.

Figure 2 shows the method used to identify the objective population, while Table 1 indicates the characteristics of the extracted subjects.

The drug consumption of the 1,084 considered patients during the 3 years of survey amounts to $€ 27,260$ in total (Table 2). The most used drugs are glucocorticoids, propionic and acetic acid derivatives, and related substances. The number of specialist services accounts for 4,005 in total.

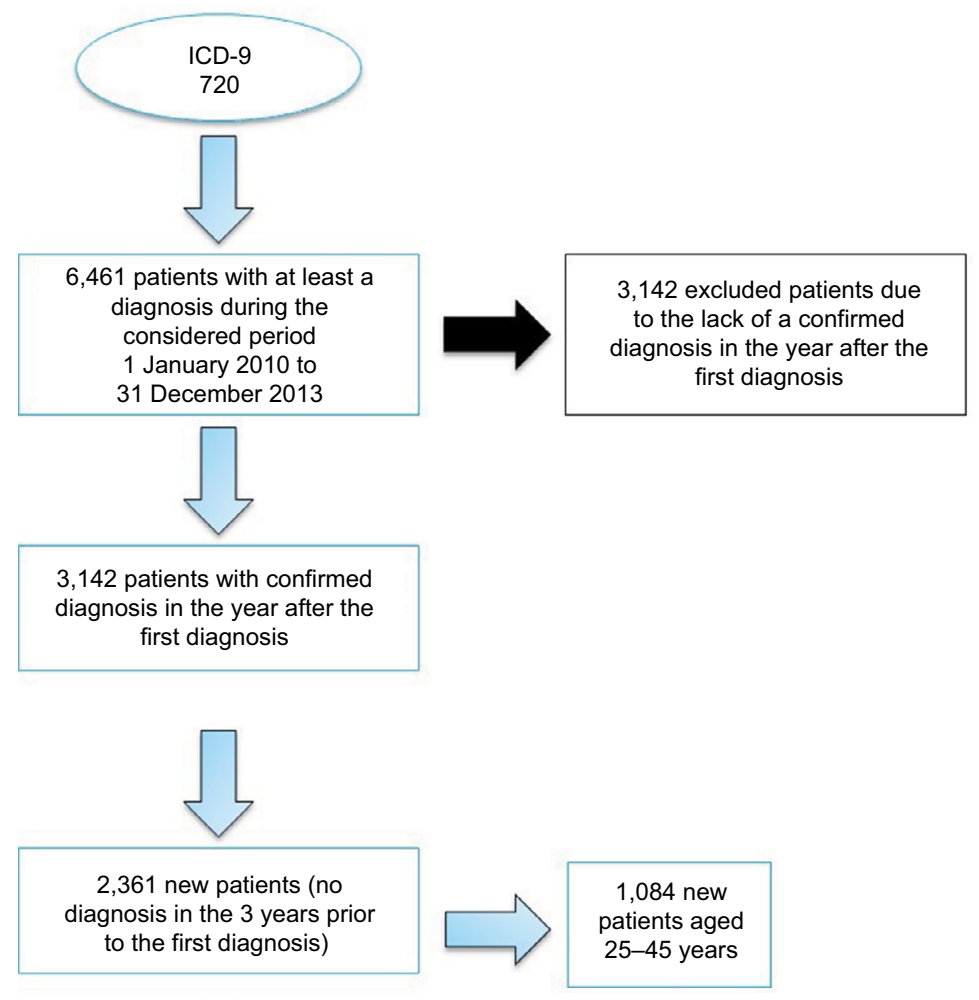

Figure 2 Selection process of new SpA patients.

Abbreviations: ICD-9, International Statistical Classification of the Diseases and Related Health Problems, version 9; SpA, spondyloarthritis. 
Table I Characteristics of enrolled patients aged 25-45 years and related diagnoses

\begin{tabular}{lll}
\hline Clinical characteristics & Patients (n) & $\%$ \\
\hline $\begin{array}{l}\text { Age (mean) } \\
\text { Sex }\end{array}$ & 43.32 & \\
Male & 381 & $35.1 \%$ \\
Female & 703 & $64.9 \%$ \\
Geographic distribution* & & \\
North East & 313 & $28.9 \%$ \\
North West & 290 & $26.8 \%$ \\
Centre & 161 & $14.9 \%$ \\
South - Islands & 290 & $26.8 \%$ \\
Charlson Index & & \\
O-I & 983 & $90.7 \%$ \\
2-3 & 91 & $8.4 \%$ \\
$\geq 4$ & 10 & $0.9 \%$ \\
SpA-related diagnoses & Diagnosis (n) & $\%$ \\
Peripheral enthesopathy and allied & 248 & $12.4 \%$ \\
syndromes & & \\
Psoriasis and related conditions & 56 & $2.8 \%$ \\
Regional enteritis, Crohn's disease, & 11 & $0.6 \%$ \\
granulomatous enteritis & & \\
Ulcerative colitis & 9 & $0.5 \%$ \\
\hline Note: & &
\end{tabular}

Note: $*$ The geographic origin of 30 patients is missing.

Abbreviation: $\mathrm{SpA}$, spondyloarthritis.

More than half of these correspond to specialist check-ups and laboratory tests, with a total expense of $€ 125,507$.

More broadly, it is estimated that in the 3 years prior to an SpA diagnosis, each patient is provided with four specialist health care services and four boxes of drugs related to undiagnosed SpA, with a total expense of $€ 140.9$.

Assuming that the Health Search database provides a representative sample of the Italian population and an inference analysis can be carried out, it may be estimated that in Italy, in the 3 years prior to an SpA diagnosis, an expense of over $€ 5.4$ million was incurred to examine and treat 38,232 new patients between 2010 and 2013 (Table 3).

\section{Discussion}

SpA is a disabling disease preventing patients from living a normal life. Early diagnosis and adequate treatment may slow the disease progression down and improve the patient's health conditions and quality of life in the short and long term. The timespan between the disease onset and the diagnosis is mainly due to difficult early diagnosis of SpA. ${ }^{17,18}$

For the first time in Italy, this work attempted to quantify the impact of the diagnostic delay, both in terms of services provided and costs incurred by the NHS. Through a retrospective analysis of the Health Search database, 1,084 subjects (aged 25-45 years) were identified. These patients produced an expense of approximately $€ 153,000$ in the 3 years prior to a confirmed SpA diagnosis, in terms of specialist check-ups
Table 2 Drug and specialist service expense of I,084 patients aged 25-45 years related to the 3 years prior to first diagnosis

\begin{tabular}{|c|c|c|c|c|}
\hline ATC code & $\begin{array}{l}\text { Drug } \\
\text { description }\end{array}$ & Patients & $\begin{array}{l}\text { Drug box } \\
\text { consumption }\end{array}$ & $\begin{array}{l}\text { Total } \\
\text { expense }\end{array}$ \\
\hline MOIAH & Coxib & 164 & 389 & $€ 6,010$ \\
\hline $\mathrm{H} 02 \mathrm{AB}$ & Glucocorticoids & 581 & 1377 & $€ 4,873$ \\
\hline MOIAE & $\begin{array}{l}\text { Propionic acid } \\
\text { derivatives }\end{array}$ & 578 & 968 & $€ 4,722$ \\
\hline M03BX & $\begin{array}{l}\text { Other centrally } \\
\text { acting muscle } \\
\text { relaxant drugs }\end{array}$ & 240 & 310 & $€ 3,799$ \\
\hline MOIAB & $\begin{array}{l}\text { Acetic acid } \\
\text { derivatives and } \\
\text { related substances }\end{array}$ & 485 & 919 & $€ 3,471$ \\
\hline M02AA & $\begin{array}{l}\text { Topical non- } \\
\text { steroidal anti- } \\
\text { inflammatories }\end{array}$ & 131 & 149 & $€ I, 762$ \\
\hline MOIAX & $\begin{array}{l}\text { Other non- } \\
\text { steroidal anti- } \\
\text { inflammatoryl } \\
\text { antirheumatic } \\
\text { drugs }\end{array}$ & 202 & 511 & $€ I, 733$ \\
\hline MOIAC & $\begin{array}{l}\text { Oxicam } \\
\text { derivatives }\end{array}$ & 99 & 182 & $€ 860$ \\
\hline $\mathrm{H} 02 \mathrm{BX}$ & $\begin{array}{l}\text { Corticosteroids } \\
\text { for systemic use }\end{array}$ & 5 & 7 & $€ 31$ \\
\hline Total & & - & 4,812 & $€ 27,260$ \\
\hline \multicolumn{2}{|c|}{ Specialist service } & Patients & $\begin{array}{l}\text { Number of } \\
\text { services }\end{array}$ & $\begin{array}{l}\text { Total } \\
\text { expense }\end{array}$ \\
\hline \multicolumn{2}{|c|}{ Magnetic resonance diagnostic } & 263 & 356 & $€ 4 I, 97 \mid$ \\
\hline \multicolumn{2}{|c|}{ Specialist check-up } & 1,012 & $\mathrm{I}, 700$ & $€ 34,445$ \\
\hline \multicolumn{2}{|l|}{ Laboratory } & 493 & $\mathrm{I}, 095$ & $€ 16,293$ \\
\hline \multicolumn{2}{|c|}{ X-ray diagnostic } & 534 & 629 & $€ \mid 4,230$ \\
\hline \multicolumn{2}{|c|}{ Related diagnostic } & 86 & 123 & $€ 9,823$ \\
\hline \multicolumn{2}{|c|}{ Scintigraphy diagnostic } & 28 & 36 & $€ 7,126$ \\
\hline \multicolumn{2}{|c|}{ Ultrasound diagnostic } & 47 & 57 & $€ \mathrm{I}, 532$ \\
\hline \multicolumn{2}{|c|}{ Physiotherapy } & 7 & 9 & $€ 87$ \\
\hline \multicolumn{2}{|l|}{ Total } & - & 4,005 & $€ \mid 25,507$ \\
\hline \multicolumn{2}{|c|}{ Total expense } & & & $€ 152,767$ \\
\hline
\end{tabular}

Table 3 Inferential analysis on the Italian resident population aged 25-45 years between 2010 and 2012

\begin{tabular}{llll}
\hline $\begin{array}{l}\text { Data referred to } \\
\mathbf{3} \text { years prior to } \\
\text { the analysis }\end{array}$ & $\begin{array}{l}\text { General } \\
\text { population (aged } \\
\mathbf{2 5 - 4 5} \text { years) }\end{array}$ & $\begin{array}{l}\text { SpA } \\
\text { patients }\end{array}$ & $\begin{array}{l}\text { Cost of } \\
\text { services } \\
\text { and drugs }\end{array}$ \\
\hline HS sample & 500,842 & 1,084 & $€ 152,767$ \\
$\begin{array}{l}\text { Inference on the } \\
\text { Italian population }\end{array}$ & $17,664,275^{\mathrm{a}}$ & 38,232 & $€ 5,387,972$ \\
\hline
\end{tabular}

Note: ${ }^{\text {Mean }}$ of resident Italian population 2010-2014.24

Abbreviation: SpA, spondyloarthritis.

and drugs, presumably not appropriately used due to a missing diagnosis. According to our assumptions, this cost represents the economic impact produced by the missed SpA diagnoses that might have been reduced if a correct and early SpA diagnostic procedure had been applied. 
If we assume that the Health Search database is a representative sample of the Italian population, it may be estimated that, in the 3 years prior to the $\mathrm{SpA}$ diagnosis, over $€ 5.4$ million were unduly spent in Italy to examine and manage 38,232 newly diagnosed SpA patients, between 2010 and 2013. The GP plays a key role and should be urged to promptly investigate suspected SpA-related back pain. In specific cases - patient's young age, inflammatory pain, often at night, alternating sciatica, family history, and concomitant diseases like psoriasis, uveitis, dactylitis, enthesitis - the GP should refer the patient to a rheumatologist.

Like all retrospective analyses on sample data in this field, this study has methodological limits. The first limit is the nature of the Health Search database. In fact, from a general medicine standpoint, it is possible that the diagnosis is not reported on time or the patient's diagnostic workup is not completed by the GP but by a specialist. In fact, of the 6,461 patients with at least an SpA diagnosis in the analyzed period, approximately $48 \%$ were not confirmed the diagnosis the following year. This may be due to a false diagnosis or to the fact that the patient is followed by a specialist and the GP has lost track of the patient. In both cases this study underestimates the real impact of the health expense.

The second limit to the analysis is linked to the identification of SpA patients and to the inclusion criteria. Specifically, the diagnosis code considered in the analysis was ICD-9 720 "Ankylosing spondylitis and other inflammatory spondylopathies." In effect, this code represents a generic value that may also include diagnoses not specifically related to $\mathrm{SpA}$, such as spinal enthesopathy (720.1), unclassified sacroiliitis (720.2) or other inflammatory spondylopathies (720.8). However, if "ankylosing spondylitis" had been associated only with code 720.2 , it would have caused an extreme loss of information due to the missed compilation of the complete code by the GP. In fact, over $80 \%$ of the ICD 9 codes considered did not have a complete codification up to the fourth digit. This also causes incidence estimates to be much higher than reported in the literature. ${ }^{3}$

Finally, it should be considered that the expense obtained by the analysis is underestimated, as it only includes the direct costs for specialist and pharmaceutical services. These costs, calculated at rate, should be added to those related to disabilities and irreversible lesions due to diagnostic delay, in addition to the costs due to the loss of productivity. ${ }^{25,26}$

In conclusion, the costs due to the delay in SpA diagnosis were quantified for the first time in Italy. For this reason, this work represents a contribution for national and regional decision makers to understand the current clinical practice and economic consequences of a diagnostic delay in the short and medium term.

\section{Acknowledgment}

The study was supported with unrestricted funding from ABBVIE, Italy.

\section{Disclosure}

The authors report no conflicts of interest in this work.

\section{References}

1. van der Linden SM, Valkenburg HA, de Jongh BM, Cats A. The risk of developing ankylosing spondylitis in HLA-B27 positive individuals. A comparison of relatives of spondylitis patients with the general population. Arthritis Rheum. 1984;27(3):241-249.

2. Ahearn JM, Hochberg MC. Epidemiology and genetics of ankylosing spondylitis. J Rheumatol Suppl. 1988;16:22-28.

3. Kaipiainen-Seppanen O, Aho K. Incidence of chronic inflammatory joint diseases in Finland in 1995. J Rheumatol. 2000;27(1):94-100.

4. Palla I, Trieste L, Tani C, Talarico R, Cortesi PA, Mosca M, Turchetti G. A systematic literature review of the economic impact of ankylosing spondylitis. Clin Exp Rheumatol. 2012;30(4 Suppl 73):S136-S141.

5. Boonen A, Mau W. The economic burden of disease: comparison between rheumatoid arthritis and ankylosing spondylitis. Clin Exp Rheumatol. 2009;27(4 supp1 55):S112-S117.

6. Ara RM, Packham JC, Haywood KL. The direct healthcare costs associated with ankylosing spondylitis patients attending a UK secondary care rheumatology unit. Rheumatology (Oxford). 2008;47(1):68-71.

7. Rafia R, Ara R, Packham J, Haywood KL, Healey E. Healthcare costs and productivity losses directly attributable to ankylosing spondylitis. Clin Exp Rheumatol. 2012;30(2):246-253.

8. Ward MM. Functional disability predicts total costs in patients with ankylosing spondylitis. Arthritis Rheum. 2002;46(1):223-231.

9. Strombeck B, Englund M, Bremander A, Jacobsson LT, Kedza L, Kobelt G, Petersson IF. Cost of illness from the public payers' perspective in patients with ankylosing spondylitis in rheumatological care. $J$ Rheumatol. 2010;37(11):2348-2355.

10. Kobelt G, Sobocki P, Mulero J, Gratacos J, Pocovi A, Collantes-Estevez E. The burden of ankylosing spondylitis in Spain. Value Health. 2008;11(3):408-415.

11. Younes M, Jalled A, Aydi Z, et al. Socioeconomic impact of ankylosing spondylitis in Tunisia. Joint Bone Spine. 2010;77(1):41-46.

12. Zhu TY, Tam LS, Lee VW, Hwang WW, Li TK, Lee KK, Li EK. Costs and quality of life of patients with ankylosing spondylitis in Hong Kong. Rheumatology (Oxford). 2008;47(9):1422-1425.

13. Torres TM, Ferraz MB, Ciconelli RM. Resource utilisation and cost of ankylosing spondylitis in Brazil. Clin Exp Rheumatol. 2010;28(4): 490-497.

14. Huscher D, Merkesdal S, Thiele K, Zeidler H, Schneider M, Zink A; German Collaborative Arthritis Centres. Cost of illness in rheumatoid arthritis, ankylosing spondylitis, psoriatic arthritis and systemic lupus erythematosus in Germany. Ann Rheum Dis. 2006;65(9): $1175-1183$.

15. Lapadula G, Marchesoni A, Armuzzi A, et al. Adalimumab in the treatment of immune-mediated diseases. Int J Immunopathol Pharmacol. 2014;27(1 Suppl):33-48.

16. Armuzzi A, Lionetti P, Blandizzi C, et al. anti-TNF agents as therapeutic choice in immune-mediated inflammatory diseases: focus on adalimumab. Int J Immunopathol Pharmacol. 2014;27(1 Suppl):11-32. 
17. Sykes M, Doll H, Gaffney K. Comment on: 'Diagnostic delay in patients with rheumatoid arthritis, psoriatic arthritis and ankylosing spondylitis: results from the Danish nationwide DANBIO registry' by Sorensen et al. Ann Rheum Dis. 2014;73(7):e44.

18. Adshead R, Tahir H, Donnelly S. A UK best practice model for diagnosis and treatment of axial spondyloarthritis. EMJ Rheumatol. 2015;2:103-110.

19. Wendling D, Claudepierre P, Prati C. Early diagnosis and management are crucial in spondyloarthritis. Joint Bone Spine. 2013;80(6) $582-585$.

20. Istituto di Ricerca della Società Italiana di Medicina Generale (SIMG). Health Search. 2016. Available from: https://www.healthsearch.it/.

21. Società Italiana di Medicina Generale (SIMG). VIII Report Health Search. Year 2013/2014 2012 ed. Firenze: Istituto di Ricerca della Società Italiana di Medicina Generale (SIMG), 2012.
22. Ministero della Salute. Remunerazione prestazioni di assistenza ospedaliera per acuti, assistenza ospedaliera di raibilitazione e di lungodegenza post acuzie e di assistenza specialistica ambulatoriale.: Pubblicato sulla GURI N. 23 del 28/01/2013 Suppl. n. 8, 2013.

23. Agenzia Italiana del Farmaco (AIFA). Prontuario farmaceuti. Medicinali; 2014. Available from: http://wwwcodifait/. Accessed June 1, 2017.

24. National Institute of Statistics [homepage on the Internet]. Resident population 2010-2012. NIS; 2016. Available from: http://demo.istat. it. Accessed November 23, 2017.

25. Malinowski KP, Kawalec P. The indirect costs of ankylosing spondylitis: a systematic review and meta-analysis. Expert Rev Pharmacoecon Outcomes Res. 2015;15(2):285-300.

26. Martindale J, Shukla R, Goodacre J. The impact of ankylosing spondylitis/axial spondyloarthritis on work productivity. Best Practice \& Research Clinical Rheumatology. 2015;29(3):512-523.

\section{ClinicoEconomics and Outcomes Research}

\section{Publish your work in this journal}

ClinicoEconomics and Outcomes Research is an international, peerreviewed open-access journal focusing on health technology assessment, pharmacoeconomics and outcomes research in the areas of diagnosis, medical devices, and clinical, surgical and pharmacological intervention. The economic impact of health policy and health systems
Submit your manuscript here: https://www.dovepress.com/clinicoeconomics-and-outcomes-research-joural

organization also constitute important areas of coverage. The manuscript management system is completely online and includes a very quick and fair peer-review system, which is all easy to use. Visit http://www.dovepress.com/testimonials.php to read real quotes from published authors. 